\title{
El Dogma: una palabra referida
}

\author{
The Dogma: a referred word
}

David de la Torre

\section{Resumen}

En la sociedad actual en la que todo es pasajero y relativo, el reflejo eclesial de juzgar el presente a partir de la verdad de la fe, que ha llegado a nosotros a través de la tradición y de su principio dogmático, no solamente es incomprendido sino seriamente cuestionado. Es necesario entonces reflexionar sobre por qué existe una dimensión dogmática en el cristianismo y mostrar con claridad su relación con el Evangelio que es Jesús, para los hombres de todos los tiempos y lugares. Ante el rechazo a la subjetividad doctrinal que domina la fe cristiana y ante el peligro permanente que ésta tiene de cosificarse en vacías fórmulas doctrinales, es preciso insistir en que el objeto de fe del cristianismo no es una lista determinada de premisas lógicas, sino la misma persona de Jesucristo. Es de Aquel que ha sido reconocido en la fe como Cristo y Señor, único Evangelio de la Misericordia del Padre, acontecimiento salvífico absoluto, de quien quieren dar testimonio los dogmas. El dogma encuentra su razón de ser en la dependencia esencial a la persona concreta de Jesucristo como verdad que libera, como camino en el tiempo hacia un Dios siempre nuevo.

Palabras claves: Jesucristo. Evangelio. Dogma. Tradición. Interpretación.

\begin{abstract}
In the present society in which everything is fleeting and relative, the ecclesiastical reflex of judging the present from the truth of the faith, that has come to us through the tradition and from its dogmatic principle; it is not only
\end{abstract}


misunderstood, but seriously questioned. It is necessary then to reflect about the reasons why there is a dogmatic dimension in the Christianity and to show with clarity its relation with the Gospel that is Jesus, for people for all times and places. Faced with the rejection to the doctrinal subjectivity that rules the Christian faith, and faced with the permanent danger of turning itself into empty doctrinal formulas, it is precise to insist on that the object of faith of the Christianity is not a determined list of logical premises, but the very person of Jesus Christ. The Dogma is intended to give testimony about the Person who has been recognized in faith as Christ and Lord, the only Gospel of the Father's Mercy, which is the absolute salvific event. The Dogma finds its reason of being in the essential dependence on the concrete person of Jesus Christ as the truth that frees, as the way through time towards an always-new God.

Keywords: Jesus Christ. Gospel. Dogma. Tradition. Interpretation.

\section{Introducción}

Para muchos de nuestros contemporáneos, el aire fresco que el papa Francisco ha aportado a la Iglesia la ha sacado - al fin - del ambiente enmohecido de sus dogmas que la hacían aparecer, a la luz pública, como una institución arcaica. Estos dogmas, que ya casi nadie entiende, serían anacrónicos en el nuevo mundo de la ciencia y la tecnología; y si la Iglesia quiere ser parte de ese nuevo mundo, estaría obligada a renunciar a su tradición dogmática para formular doctrinas más acordes a los tiempos modernos; esperando suscitar así, la adhesión fervorosa de las masas que la han desertado desde hace mucho tiempo. Si tan mala prensa tienen los dogmas, quizás no es solamente porque el lenguaje que utilizamos ya no dice nada, sino también porque hemos olvidado el lazo matricial que debe haber entre todo dogma y el Evangelio que no es simplemente un texto sino la persona misma de Jesús ${ }^{1}$.

\footnotetext{
1 "Para nadie constituye un misterio el significado peyorativo con que el término dogma es usado en el lenguaje corriente. "Dogmático" según el "Diccionario de la Real Academia" significa "inflexible, que mantiene sus opiniones como verdades inconcusas" (...) Sin embargo, las palabras no se desvirtúan porque sí. El empeorar de su significado, eso quiere decir peyorativo, no es fortuito, sino que es reflejo de un existir histórico (...) está condicionado por un olvido o alienación del carácter evangélico y personal del mensaje cristiano". NOEMI, Juan. "Sobre la credibilidad del dogma cristiano". Teologia y Vida XVL (2004), p. 261.
} 
Nos encontramos entonces ante la necesidad de reflexionar sobre el porqué de una dimensión dogmática en el cristianismo y de buscar, en caso de que haya, su valor evangélico, es decir, su relación con el Evangelio que es Jesús para los hombres de todos los tiempos y lugares. Una comprensión aguda y clara de este tema podrá ayudarnos a comprender que la Reforma de la Iglesia, es siempre, fidelidad creativa a la Tradición en el hoy de cada momento histórico, de que la fe no responde a lo que la conveniencia del momento nos exigiría, sino al testimonio de la Verdad Encarnada portado por la comunidad creyente a riesgo de su propia vida.

\section{La normatividad de la fe cristiana}

El carácter obligatorio y normativo que relacionamos a la palabra "dogma" en el vocabulario de la regulación de la fe es una herencia del siglo XIX. Pero, la realidad que recubre ese término ya existe desde el principio del cristianismo. La cuestión de la "norma" o de la normatividad de la fe atraviesa estructuralmente los primeros discursos cristianos. Existe, en el Nuevo Testamento, una conciencia viva de que la fe cristiana implica una normatividad, y que debe guardar su autenticidad.

... ya antes de que nacieran los escritos que componen el Nuevo Testamento existían fórmulas de confesión, credos, fijos y vinculantes que, por ejemplo, Pablo toma de la tradición y los transmite a otros: "Pues, a la verdad, os he transmitido, en primer lugar, lo que yo mismo he recibido" $(1 \text { Co } 15,3 ; 11,23)^{2}$.

La fe de las comunidades neo-testamentarias no se basa en el testimonio privado de algunos individuos, sino en una confesión de fe común a todos, pública y obligatoria que precede la redacción del Nuevo Testamento ${ }^{3}$. Así

\footnotetext{
${ }^{2}$ KASPER, Walter. Teología e Iglesia. Barcelona: Herder, 1990, p. 94. Esta realidad incontestable permite afirmar a W. Kasper "el kerygma de Jesucristo es esencialmente dogmático. Esto exige un sí o un no definitivo, inconfundible, absolutamente claro", p. 84.

${ }^{3}$ Estas confiesan la fe en Jesús como Cristo (Mt 16,16 et par), Kyrios (Rm 10,9; 1 Co 12,3; Ph 2,11) e Hijo de Dios (Mt 14,33; 16,16; Jn 1,34.48; 1Jn 4,15; 5,5, etc) Dan testimonio de la fe en la muerte y en la resurrección de Jesús (1Co 1,3-5; 1Th 4,14; Rm 8,34;14,9, etc); proclaman su misión y su nacimiento (Ga 4,4), el sacrificio de su vida ( $\mathrm{Rm} \mathrm{4,25;8,32;} \mathrm{Ga} \mathrm{2,20} \mathrm{etc)} \mathrm{al} \mathrm{igual}$ que su parusía (1Th 1,10; Ph 3,20 et s.) La divinidad de Jesús, su encarnación y su exaltación son alabadas en himnos (Fi 2,6-11; Col 1,15-20; 1Tm 3,16; Jn 1,1-18).
} 
mismo, durante la época Patrística, todos los Padres tuvieron la preocupación de defender la integridad del Evangelio sin ninguna complacencia con el error. Por esta razón, Concilios locales se reúnen a partir de finales del siglo II, y el siglo IV verá la realización del primer concilio ecuménico en Nicea ${ }^{4}$. El proceso de regulación de la fe existe incluso si no hay aún una palabra técnica para enunciarlo, ya que el empleo del término "dogma" sigue siendo impreciso ${ }^{5}$. En Occidente este término - aunque ausente de Tertuliano, Cipriano, Agustín - va a comenzar a desempeñar un papel importante en el discernimiento eclesial entre la verdad y el error a nivel doctrinal. Vincent de Lérins $(+450)$ empleará por primera vez el término "dogma" en su libro " $E l$ Commonitorium" en busca de los criterios que permitan este discernimiento.

... en la Iglesia Católica incluso, es necesario velar con el mayor cuidado lo que debe considerarse como verdad lo que ha sido creído en todas partes, siempre y por todos (quod ubique, quod se, quod ab autobus creditum es) ya que no es realmente católico, en sentido pleno del término, que lo que percibe el carácter universal de toda $\operatorname{cosa}^{6}$.

Aunque el libro de Lérins no desempeñará ningún papel en la Edad Media, se redescubrirá en el siglo XVI, en las controversias con los protestantes ${ }^{7}$. Así, los primeros testigos del empleo del término de "dogma" en sentido limitado, es decir, con esta exigencia de ortodoxia probada y juzgada, serán el francés François Véron (1578-1649) y el inglés Enrique Holden (1596-1662). Pero,

\footnotetext{
${ }^{4}$ Ireneo de Lyon, por ejemplo, en sus disputas con los gnósticos, afirmará con vigor que la verdad del Evangelio se manifiesta en la Tradición que viene de los apóstoles y que es en el seno de la Iglesia que esta puede ser percibida por todos. Cf. IRENEO DE LYON. Contra los Herejes III, 3,1.

${ }^{5}$ Tiene el sentido de decreto (Cf. CLEMENTE DE ROM., A los Corintios 27,5), enseñanza, frecuentemente una instrucción moral de Cristo (Cf. IGNACIO DE ANTIOQUIA. A los Magnesianos 13,1). En la Edad Media, el término es raramente utilizado. Para expresar lo que nosotros entendemos hoy por dogma , Santo Tomás, por ejemplo, habla de "artículos de fe" (ST IIa-IIae, q. 1, a. 6). Cf. KASPER, Walter. Dogme et Evangile. Tournai: Casterman, 1967, pp. 32-33.

${ }^{6}$ VINCENT DE LÉRINS. Commonitorium, 23,3; CCSL 64, p. 149; trad. M. Meslin, Namur: Soleil Levant, 1959, p. 39, citado por SESBOÜÉ, B. Histoire des Dogmes IV. Paris: Desclée, 1996, p. 63.

${ }^{7}$ Se apoyan en la fórmula de Lérins para referirse a lo que en la Iglesia "ha sido creído por todos lados, por siempre y por todo el mundo". Se eleva así esta fe antigua y universal al rango de dogma divino, celeste, eclesial y se lo opone a las innovaciones del nuevo dogma. Cf. KASPER, Walter. Dogme et Évangile. Paris: Casterman, 1967, p. 34.
} 
es el franciscano Phillippe Néri Chrismann (1751-1810), dos siglos más tarde, quien va a generalizar esta concepción: “...un dogma de fe no es otra cosa que una doctrina y una verdad divinamente revelada, doctrina y verdad que el juicio público de la Iglesia propone a creer de fe divina, de modo que su contrario sea condenado por la misma Iglesia como doctrina herética"s.

La fórmula fue calificada de "minimalista" y la edición de la obra de Chrismann en 1854 fue puesta al Índex. Sin embargo, en el siglo XIX, esta se volverá el bien común de la teología católica ${ }^{9}$. Es el Concilio Vaticano I que, retomando casi textualmente la fórmula de Chrismann, consagra definitivamente el uso de la palabra dogma para calificar el carácter obligatorio y normativo de algunas posiciones adoptadas por el Magisterio eclesial en lo que se refiere a la $\mathrm{fe}^{10}$.

... se debe creer de fe divina y católica todo lo que es contenido en la palabra de Dios, escrita o transmitida por la tradición, y que la Iglesia propone a creer como divinamente revelado, o por un juicio solemne, o por su magisterio ordinario y universal (Dei Filius, Dz 1792).

El proceso de regulación de la fe que existía, como lo dijimos, desde antes del Nuevo Testamento y que no dejó de animar la vida de la Iglesia, tiene ahora un término técnico, pero este recorrido histórico de la formulación del concepto no nos ha dicho todavía lo que es el dogma en la economía cristiana. Algunas cuestiones deben encontrar una respuesta. ¿Este proceso puede entenderse teológicamente? ¿Tiene algún valor evangélico? ¿No es acaso el simple reflejo de la necesidad sociológica de mantener a toda costa la unidad a golpe de decisiones autoritarias y compromisos? La Crisis Modernista, por ejemplo, planteará estas cuestiones con fuerza y gravedad ${ }^{11}$.

\footnotetext{
${ }^{8}$ CHRISMANN, Ph. Néri. La règle de la foi catholique. Kempten, 1792; trad in KASPER, Walter. Dogme et Évangile, p. 35.

${ }^{9}$ Como lo señala Y. Congar es únicamente en el s. XVIII que los documentos eclesiásticos emplean la palabra en su sentido moderno estricto, pero hablan de dogmas o de tal dogma (DsZ 2629), no del dogma, como se hará después del s. XIX. Ese sentido se va afirmando poco a poco gracias al desarrollo, a partir del s. XVI siècle de una teología del magisterio, sobre todo del magisterio pontifical, "definiendo" las verdades de fe. Cf. CONGAR, Yves. La Foi et la Théologie. Paris: Desclée, 1962, p. 55.

${ }^{10}$ Según W. Kasper esta "concepción estrecha del dogma asegura una campo apreciable de libertad en la Iglesia" ya que no se puede presumir la obligación de creer tal o tal punto. Esto debe ser establecido estrictamente para cada punto. Cf. KASPER, Walter. Dogme et Évangile, p. 39.

${ }^{11}$ Es precisamente en estos términos que la pregunta es planteada en 1905, en el momento más
} 
En un esfuerzo por tener en cuenta la distancia histórica que nos separa de los primeros testigos de la fe y las prácticas eclesiales que tomaron forma en un contexto histórico que ya no es el nuestro, hay teólogos que consideran el dogma como una palabra eminentemente jurídica. B. Sesboüé en su artículo " $\mathrm{el}$ Proceso Contemporáneo de Calcedonia", consagrado a la mirada crítica que la teología contemporánea porta sobre la definición cristológica del Concilio de Calcedonia, nos propone una concepción del dogma en ese sentido ${ }^{12}$. Nuestro autor pretende hacer del dogma una especie de llamado al trabajo indispensable que la comunidad cristiana debe realizar para dar razón de su esperanza en la realidad histórica presente $(1 \mathrm{P} 3,15)$. B. Sesboüé, conquistado por la hermenéutica jurídica que H.G. Gadamer desarrolló en su libro “Verdad y Método" 13 - y que podría resumirse así: el intérprete se encuentra vinculado por un texto normativo que debe aplicar a un caso particular - define el dogma como "una palabra eminentemente jurídica en su forma: se trata de una decisión, de un decreto portado por la comunidad constituida en la persona de sus representantes oficiales y responsables, e incluso de una frase que define un problema planteado y se impone a la adhesión de todos: hace ley"14.

Esta concepción es, sin duda, muy seductora. Fomenta ardientemente el trabajo del teólogo para dar cuenta de la fe de la Iglesia, ya que inscribe la petición de interpretación no simplemente de nuestro lado, sino del lado de la declaración dogmática misma: solicita nuestra interpretación, se trata nada menos que de su razón de ser. Pero, es necesario decirlo, quedarnos en una definición jurídica del dogma nos conduce paradójicamente a un callejón sin salida y a la negación de lo que quiere provocar.

Es cierto que la palabra dogmática de la Iglesia puede verse "en su forma" como un acto jurídico, pero no podemos reducir el dogma a una simple ley a la cual estaríamos sujetos, aún hoy, a precio de una reinterpretación perpetua. Tomemos el ejemplo de la ley civil: ella misma no es un simple "código" que debe descifrarse sin cesar. Su letra remite siempre a una "tradición". Se

agudo de la crisis moderna, por E. Le Roy (1870-1954). Cf. LE ROY, E. “Qu'est-ce qu'un dogme". La Quinzaine 63 (1905), pp. 495-526. Para la referencia histórica de la cuestión. Cf. POULAT, Emilie. Historia, Dogma y Crítica. Madrid: Ed Taurus, 1974; y THEOBALD, C. "Qu'est-ce qu'un dogme? La crise moderniste et ses répercussions sur le système doctrinal du catholicisme”. In: Histoire de Dogmes IV. Paris: Desclée, 1996, pp. 383-422.

${ }^{12}$ Cf. SESBOÜÉ, B. "Le procès contemporain de Chalcédoine. Bilan et perspectives". RSR 65/1 (1977), pp. 45-84.

${ }^{13}$ GADAMER, H.G. Vérité et Méthode. Paris: Seuil, 1976, p. 347.

${ }^{14}$ SESBOÜÉ, B. art. cit., p. 57. 
estructura por una tradición, y al mismo tiempo, una vez que vio la luz no se pone en órbita, se integra a la tradición, la estructura. El derecho alemán no es el derecho francés, y aunque la letra de cualquier ley particular puede ser similar en los dos derechos, su papel estructurante del vínculo social no es nunca independiente de su carácter ya estructurado por la tradición, en la cual tomó cuerpo de una manera específica y única. Un historiador puede detener su reflexión sobre el dogma en su concepción jurídica, un teólogo no.

B. Sesboüé, que no olvida que toda ley particular siempre se refiere a una ley fundamental, llega a definir el vínculo entre dogma y Escritura según este principio jurídico ${ }^{15}$. Afirma que el dogma es "un acto de interpretación del mensaje fundador inscrito en la Escritura" es decir, es relativo a una "ley fundamental" que lo sobrepasa y que lo vincula. Y añade: "la palabra dogmática no es nada más que un acto de jurisprudencia que permite a la comunidad histórica vivir auténticamente de la 'ley'que le da la existencia"16. Esta concepción que hace de la Escritura una "ley fundamental" es tan desconcertante que el mismo B. Sesboüé intenta matizar su posición afirmando que la hermenéutica jurídica de Gadamer no es aplicable a la Escritura ya que si "hace autoridad y permanece la primera autoridad, ella no tiene la forma de la ley, es mensaje del acontecimiento fundador y liberador"17, pero permanece convencido de que esta concepción nos ayuda a entender la esencia y la función de las declaraciones dogmáticas en la vida de la Iglesia.

Además, B. Sesboüé remite tanto el dogma a su contingencia espaciotemporal que se vuelve "accidental": no es más que la señal de una crisis que no habría debido ocurrir. De la misma forma, escribe B. Sesboué,

... que la redacción de un artículo de derecho se modela sobre las infracciones que se producen con el fin de suprimirlas, y que pretende responder a un problema de bien común planteado por la actualidad, así mismo [el dogma] se produce cuando lo que era objeto de una "posesión pacífica" se encuentra cuestionado, deformado, contestado, o incluso formalmente negado, o al menos que da lugar a una aporía creadora de incertidumbre ${ }^{18}$.

\footnotetext{
${ }^{15}$ En nuestros países democráticos, la Constitución ocupa este lugar jurídicamente privilegiado. Es así que las leyes no son sino una aplicación de la Constitución en lo concreto de la vida social.

${ }^{16}$ SESBOÜÉ, B. art. cit., p. 57.

${ }^{17}$ SESBOUÉ, art. cit., p. 58.

${ }^{18}$ SESBOUÉ, art. cit., p. 58.
} 
Es por esto, que condicionada por una situación concreta, la palabra dogmática da "una interpretación reguladora del mensaje de fe atestiguado en la Escritura; como ley es una ley de lectura referente a un punto preciso; esta es la razón por la que es siempre parcial y hace hincapié en el 'es necesario"'19.

Así la palabra dogmática de la Iglesia entendida como un acto jurídico que quiere poner fin a una crisis, no es ya, según B. Sesboüé, "a recibir" en un vínculo vivo con la tradición, sino "a tener en cuenta" a la hora de leer el Nuevo Testamento. Todo eso en un planteamiento más intelectual que existencial, como si bastara de una interpretación más afinada para descubrir su verdad, como si el dogma no formara parte de la Paradosis de la Iglesia que alimenta la fe y la vida de los cristiano ${ }^{20}$. El dogma considerado de esta manera tan formal puede hipotéticamente ser portador de sentido y vida para la comunidad cristiana; es reducido a la paráfrasis simbólica de la conciencia eclesial en un momento determinado de su historia, sin contribuir en ningún caso a vivificar y transformar el presente de esta conciencia eclesial ${ }^{21}$.

Aunque metodológicamente hablando, uno puede estar perplejo por la aplicación de algunas páginas de "Verdad y de Método"22 la posición de B. Sesboüé es loable. Él plantea la cuestión del sentido y de la importancia del dogma para el hombre de hoy. Pero, al retener únicamente de Gadamer un aspecto de su método hermenéutico, olvida que lo que está en cuestión en la obra de Gadamer "no es lo que hacemos, ni lo que debemos hacer, sino lo que ocurre con nosotros, más allá de nuestro querer y de nuestro hacer"23, es decir, "la verdad". Así, al concentrarse en el problema del significado del dogma para el hombre de hoy, B. Sesboüé pierde de vista la cuestión de su verdad, lo separa de su conexión con la Paradosis, y lo aísla de la fe vivida de la Iglesia,

\footnotetext{
${ }^{19}$ SESBOUÉ, art. cit., p. 58.

${ }^{20}$ Esto es confirmado por algunas líneas de su libro, Le Magistère à l'Épreuve, donde B. Sesboüé escribe: "La recepción es un evento que tiene un fin. Al término de un proceso complejo, que comporta reanudaciones, el concilio pasa a ser objeto de posesión apacible por todos los que lo reciben. Cuando el mundo cultural, que ha visto esta reunión, se transforma, el concilio y su recepción se hacen un bloque, como un todo que pertenece a lo capital de la fe, pero no se dirige a los creyentes de la misma manera. Un concilio será siempre objeto de una hermenéutica, no es verdaderamente objeto de recepción." SESBOÜÉ, B. Le magistère à l'épreuve. Paris: DDB, 2001, p. 92.

${ }^{21}$ Cf. METZ, J.-B. La foi dans l'histoire et dans la société. Paris: Cerf (CF 99), 1999, pp. 205-229.

${ }^{22}$ GADAMER, H.G. op. cit., pp. 166-184.

${ }^{23}$ GADAMER, H.G. op. cit. Préface à la seconde édition, p. 8 .
} 
del encuentro con Jesús ${ }^{24}$. En nuestra búsqueda por una comprensión de lo que es el dogma, debemos, pues, recorrer otros caminos.

El análisis histórico de la palabra dogma (...) aboca a una constatación o estado de cosas sorprendente: la utilización del término dogma en el sentido que lo utiliza el Vaticano I es de reciente data en el vocabulario teológico, siglo 18, y todavía más reciente en el magisterial, siglo 19 . Este uso está determinado por un contexto polémico antiprotestante y antimoderno. Para Kasper, estamos en presencia de un estrechamiento, de un tránsito "desde un concepto más amplio a uno más restringido de dogma", "desde una fundamentación de contenido teológico a una de tipo jurídico-formal". Condicionado por un afán polémico objetivizante, se prescinde de la dimensión subjetiva que comporta el creer, de la concreta "apropiación y recepción que tiene lugar en la Iglesia" de aquello que se cree; se aísla, desvirtuando su significado global, el contenido de la fe en cuanto formulación hecha del sujeto que la formula ${ }^{25}$.

\section{Una palabra amasada de Evangelio}

Si es verdad que el hombre en su búsqueda de la Verdad nunca encuentra lo real como un fenómeno "anodino y anónimo", es necesario también considerar que en este encuentro nunca parte de cero, otro antes de él recorrió ya este camino de reconocimiento y dejó al borde del camino las huellas de su paso en forma de testimonio. Además, a pesar del hecho de que el hombre se sitúa siempre históricamente, presuponemos que existe siempre la verdad, así como algunas verdades fundamentales, por ejemplo la declaración según la cual la vida humana debe preservarse de manera absoluta. No hay, pues, conocimiento humano sin testimonio, y sin una estructura de precomprensión y de "prejuicios" estructurales. Eso significa como lo muestra W. Kasper en su libro "La Teología y la Iglesia"26 que la verdad revelada solo se transmite en la Paradosis de la Iglesia, que la palabra dogmática como acto de fe eclesial referido por esencia a la Escritura sólo puede entenderse dentro de la tradición

\footnotetext{
${ }^{24}$ El dogma, como lo veremos más adelante, debe ser considerado dentro de su función de mediación obligatoria de la verdad revelada.

${ }^{25}$ Cfr. NOEMI, Juan. art. cit., p. 261.

${ }^{26}$ Visión que será retomada casi textualmente por la Comisión Teológica internacional en un documento titulado "L'interprétation des dogmes", nada raro ya que el documento fue preparado bajo la dirección del mismo W. Kasper. Cf. Doc. Cath. º2006 (1990) pp. 489-502.
} 
y de la vida de la Iglesia. Hay que romper con una tradición ampliamente extendida en la teología católica que sitúa el dogma fuera de la tradición y lo absolutiza por encima de cualquier otra dimensión de la vida eclesial.

En toda comunicación, por el lenguaje, efectuamos cada vez la preaprehensión de una dimensión absoluta. Todos los días hacemos la experiencia de que en afirmaciones condicionadas históricamente, pueden expresarse de manera anticipatoria realidades válidas para siempre. Por esto, sin un mínimo de convicciones y valores fundamentales comunes, ningún hombre y ninguna sociedad pueden subsistir. En este sentido, según W. Kasper, "todo hombre lleva una existencia dogmática" "27. ¡Se trata nada menos que de su vida y de su muerte! No es necesario, pues, negar bajo pretexto de defender la libertad evangélica, el hecho de que haya también un principio dogmático en la Iglesia ya que éste se articula sobre una determinada estructura dogmática de la existencia y del comportamiento humano.

W. Kasper no pretende justificar primeramente, la existencia de los dogmas (al plural) en el cristianismo sino el de renovar su principio dogmático ${ }^{28}$. En efecto, no podemos aún sostener que este principio dogmático deba tomar una forma dogmática. Pero, si "el centro del kerigma cristiano es el mensaje que anuncia que en Jesucristo el absoluto, que se presupone de manera abierta e indeterminada en todo conocimiento, entró de manera determinada y definitiva en las condiciones de la historia"; y si el "contenido del mensaje cristiano no puede separarse de la forma de su comunicación", resulta que "al contenido absoluto y determinado del mensaje cristiano corresponde por lo tanto una forma absoluta y determinada: la forma del discurso dogmático"29. El kerigma cristológico exige el dogma y su pretensión a ser definitivo como uno de sus elementos constitutivos esenciales e inalienables. Eso significa, entre otras cosas, que sin la fe de la Iglesia que lo confiesa de manera definitiva, el acontecimiento Jesucristo se habría desvanecido en la historia sin efecto ${ }^{30}$.

La fe cristiana no tiene por "objeto", como se podría suponer, lo que es "eterno" y que en virtud de su alteridad permanecería completamente fuera de nuestro mundo y fuera de nuestro tiempo; su "objeto" es más bien Dios que

\footnotetext{
${ }^{27}$ Cf. KASPER, W. Evangelio e Iglesia, p. 43.

${ }^{28} \mathrm{Si}$ el hecho de ciertas opiniones últimas es afirmado, el contenido universalmente normativo de una opinión determinada no es adquirido aún.

${ }^{29}$ KASPER, W. La Théologie et l'Église, pp. 126-127.

30 "Confesar que la Iglesia se mantiene siempre en la verdad, es pues una parte integrante de la confesión de Cristo mismo”. KASPER, W. La Théologie et l'Église, p. 44.
} 
entró en la historia, Dios hecho hombre. Su pretensión de ser revelación se funda en el hecho de que introduce el Eterno en nuestro mundo: "Nadie nunca ha visto a Dios; el Hijo Único Engendrado, que está en el seno del Padre, se lo hizo conocer" (Jn 1,18). Es por el hápax $(\mathrm{Hb} 7,27)$ de la revelación histórica de Cristo que el dogma es posible ${ }^{31}$. Su razón de ser la encontramos no en una serie infinita de revelaciones sino en el Evangelio, acontecimiento histórico definitivo de la salvación, en Jesucristo con quien nosotros seguimos encontrándonos hoy gracias a la tradición eclesial que no es otra que la tradición apostólica ${ }^{32}$.

El evangelio es la fuerza del Señor resucitado en y sobre la Iglesia por medio de su palabra viva. El evangelio no es ninguna cantidad pretérita, sino una fuerza presente que se expresa de manera siempre nueva en la confesión y testimonio de la Iglesia, pero que no se agota en la misma. (...) El dogma es una manera como se atestigua en la Iglesia el evangelio de la venida escatológica de Cristo. Un dogma es el acontecer provisorio de la verdad escatológica y definitiva de Cristo ${ }^{33}$.

Por otra parte, como siempre lo ha sostenido la teología católica, la verdad de Dios, con Jesucristo, no habría venido definitivamente a la historia, si en el Espíritu Santo, que nos recuerda cada vez de nuevo a Jesucristo y que nos conduce hacia la Verdad (véase Jn 14,26; 16,3), esta no fuese recibida públicamente y confesada por la comunidad de fieles. El testimonio de fe de la comunidad de creyentes, es decir, de la Iglesia, representa, por lo tanto, un elemento constitutivo de la propia Revelación.

Sólo en la Iglesia y por ella, la revelación de Cristo llega a su término.

\footnotetext{
${ }^{31}$ Con K. Rahner, es necesario sostener que el enunciado dogmático en el sentido estricto, no es idéntico a la palabra original de la revelación ni con el enunciado original de la fe tal como ellos están consignados en la Escritura. Esta distinción no es una separación, al punto de oposición. Pero hay una diferencia esencial entre el enunciado dogmático y el testimonio original de la fe cuyo hecho sin embargo parte de la Escritura en su totalidad. Este enunciado que no es uno con la Escritura es la condición de posibilidad que permite al cristiano posterior al tiempo apostólico entender con obediencia y repetir el enunciado original de la Buena Noticia venida de Jesucristo y teniendo a Jesucristo por objeto y por fin, sin ser antihistórico ni antieclesial. Cf. RAHNER, K. “Qu'est-ce qu'un énoncé dogmatique?" In: Écrits Théologiques 7. Paris: DDB, 1967, pp. 239-241. En adelante utilizaremos ED para citar este texto, seguido del número de la página.

${ }^{32}$ Cf. ALCAÍn, José Antonio. La Tradición. Bilbao: Universidad de Deusto, 1998.

${ }^{33}$ KASPER, Walter. Dogma unter dem Wort Gottes. Maguncia, 1965, pp. 24 y 128.
} 
Sólo en la Iglesia y por ella, permanece en el mundo y es efectiva. Es decir, la verdad de la revelación de Dios en Jesucristo no sólo fue recibida por el pueblo que reunió, sino que permanece portada por ese pueblo. La estructura primera no es un texto sino la tradición de un acontecimiento que es siempre acontecimiento de tradición. Es en el centro de este testimonio, portado por los cristianos, que la verdad de la Palabra de Dios hace autoridad y se hace reconocer en la fe. La propia Escritura es considerada como tal, al ser portada por la tradición viva de la confesión de fe, que la canoniza y en la cual toma sentido.

No tenemos, de ninguna manera, la intención de minimizar la autoridad de la Escritura, "norma normans no normata" de todas nuestras declaraciones dogmáticas, como certificado normativo del Evangelio de Dios entre los hombres. Queremos destacar que no funciona sola. Tomada en su materialidad, sigue siendo una "escritura"; solo se convierte en Escritura en función de la Iglesia, que nos la transmite como expresión de la Palabra de Dios desde la experiencia de haberse encontrado con Jesús en Iglesia. Es la Iglesia apostólica que la trabajó; es la Iglesia post-apostólica que le dio su cierre a través de la constitución del Canon. Es la Iglesia que le da autoridad. Eso significa que la verdad de Jesucristo se mediatiza, se actualiza de manera humana e histórica a través del conjunto de la vida y de actuar de la Iglesia, es decir, también a través de las declaraciones dogmáticas a condición de que se refieran constantemente a su lugar matricial que es la Iglesia y que no sean idolatradas como algo que estaría por encima de la Iglesia o independiente de toda su vida ${ }^{34}$.

Afirmar el carácter evangélico del dogma cristiano comporta hacerse
cargo del horizonte dialógico que se establece entre la persona misma
de Jesús y la del creyente. Este horizonte no es un más allá del dogma,
sino que constituye su misma condición de posibilidad y lo constituye
radical y dinámicamente en su in-esse desde el punto de vista teológico. El

34 "La Iglesia es el sacramento, a la vez que, signo e instrumento de la Parusía. Ella anuncia el Evangelio de las obras salvíficas de Dios (martyria); ella transmite la confesión de fe a los que bautiza (Rm 6,17); ella confiesa su fe al partir el pan y en su oración (leiturgia, Hch 2,42); ella sirve a Cristo en los pobres, los perseguidos, los cautivos, los enfermos y los moribundos (diakonia, Mt 25). Los dogmas son una expresión de esta misma tradición de fe dentro del orden doctrinal". COMMISSION THÉOLOGIQUE INTERNATIONALE. "L'interprétation des dogmes". In: DC N²006 (1990), p. 499. En adelante, para citar este texto utilizaremos CTI seguido del número de página. 
enunciado dogmático se sostiene solo como vehículo de un acontecimiento entre el creyente y la persona de Jesús, que es la "cosa" que lo origina y termina ${ }^{35}$.

Además, si como lo mostró K. Rahner "escuchar la Palabra" es una actividad humana inserta en la carne de nuestras lógicas, nuestras expectativas, y nuestros conceptos ya presentes, es necesario también afirmar que la declaración kerigmática más simple contiene ya, de una manera legítima y necesaria, una experiencia y una reflexión sobre esa experiencia que quiere ser normativa en el orden de la fe; una declaración dogmática es, pues, una "continuación" de esta reflexión originaria que hace una sola cosa con el acto originario de escuchar hoy a ese Dios que toma carne también en el vacío de nuestros conceptos y de nuestros lenguajes.

En ese sentido, la declaración dogmática no es, pues, una simple declaración profana sobre un objeto teológico, sino un ejercicio de la virtud de fe. No es el fruto simplemente de la curiosidad especulativa del conocimiento humano sobre las cosas divinas. Tiene su razón de ser en la fe, no porque su verdad superaría los límites de nuestro conocimiento, sino porque la fe exige que creyéndola en todas las épocas haga un trabajo de inteligencia y discernimiento con relación a lo que cree, y este planteamiento no puede en ningún momento disociarse de la propia fe. No es una declaración simplemente referida al contenido de la fe (fides quae creditur) sino que él mismo se vincula intrínsecamente con el acto de creer (fides qua creditur) ya que la fe es desde el principio fides illustrata ${ }^{36}$.

La declaración dogmática no puede nunca separarse de su origen, de la propia fe vivida en Iglesia; si lo hace, pierde su base y se vuelve vacía. Esto nos prohíbe, pues, oponer pura y simplemente fe y declaración dogmática como era la tentación del Modernismo ${ }^{37}$.

Como lo dijimos, toda declaración dogmática tiene la pretensión de decir en toda verdad "algo" de Dios mismo y, como nos lo recuerda toda la teología católica, a pesar de que nunca nuestras palabras serán aptas para hablar de Dios, tenemos la obligación de romper el silencio. Sin embargo, como lo indicó W. Kasper, a la hora de hablar de Dios, no es solamente la insuficiencia del lenguaje humano que está en cuestión sino también su historicidad. "El

\footnotetext{
${ }^{35}$ NOEMI, J. art.cit, p. 262.

${ }^{36} \mathrm{Cf}$. ED 222.

${ }^{37}$ Cf. ED 222-223.
} 
lenguaje dogmático releva de una cultura determinada con sus posibilidades de expresión siempre limitadas". Hablan la lengua de su tiempo, "lo que afirman de manera definitiva se articula cada vez según condiciones que son las de la historia" 38 . En ese sentido, el mismo Juan XXIII invitaba a los Padres del Concilio Vaticano II a distinguir entre el contenido dogmático normativo que permanece y la forma de expresión de este contenido que varía en la historia ${ }^{39}$.

Si aceptamos que el "contenido" del dogma se identifica con la persona de Jesucristo reconocida en la fe como evangelio de Dios por el creyente, entonces tiene un inextirpable carácter histórico. El enunciado dogmático resulta para nosotros una realidad histórica por partida triple. Primeramente en cuanto precipitado de un acontecimiento histórico pasado originante, la historia del judío nacido de María que murió crucificado bajo el mandato de Poncio Pilatos en Palestina hace dos milenios. En segundo lugar porque supone el reconocimiento del mismo Jesús crucificado como resucitado y Cristo por una comunidad que explicita y consigna solemnemente su fe y, en tercer lugar, porque hoy pretende interpelarnos como verdad que nos concierne aquí y ahora. Podría decirse que el dogma cristiano tiene una dimensión histórica en cuanto verdad dada (datum), heredada (traditum) y que interpela en el presente concreto (quaesitum). Esta inextirpable persistencia del carácter histórico del dogma se funda positivamente en su pretensión de ser testimonio de la verdad de una historia concreta (la de Jesús) como logos último y definitorio de sentido para la historia de toda la humanidad, es decir, como escato-logos de la historia ${ }^{40}$.

Eso significa que la enseñanza de la Iglesia, conservando siempre el mismo sentido y el mismo contenido, debe transmitirse a los hombres de una manera viva y correspondiendo a las exigencias de su tiempo. Toda declaración dogmática es el fruto de una confrontación obediente entre la existencia del hombre declinada al presente y el kerigma de la salvación transmitido en Iglesia y por la Iglesia, siempre referido al acontecimiento de Jesucristo del cual nosotros también nos convertimos en testigos. En esta confrontación, Cristo se vuelve presente en el hoy de un tiempo dado, y en este sentido, hay

\footnotetext{
${ }^{38}$ KASPER, W. La Théologie et l'Eglise, p. 125.

${ }^{39}$ Una cosa es la substancia de la antigua doctrina, del "depositum fidei", y otra la manera de formular su expresión; y de ello ha de tenerse gran cuenta - con paciencia, si necesario fueseateniéndose a las normas y exigencias de un magisterio de carácter predominantemente pastoral. Juan XXIII. "Discurso de apertura del Concilio, el 11 octubre de 1962". AAS 54 (1962), p. 792. ${ }^{40}$ NOEMI, Juan. art. cit., p. 263.
} 
en la tradición eclesial una realidad que recubre el carácter obligatorio de la fe, el dogma.

Este reconocimiento de la historicidad de las declaraciones dogmáticas se profundizó después del concilio Vaticano II, enfrentando el peligro de un relativismo dogmático en la declaración Mysterium Ecclesiae (1975) de la Congregación para la Doctrina de la $\mathrm{Fe}$, y en el documento de la Comisión Teológica Internacional (CTI) titulado "La interpretación de los dogmas" (1990). Se subrayó así que, en cualquier caso, los dogmas en su forma históricamente determinada son verdaderos y normativos ${ }^{41}$. W. Kasper desarrolla esta idea fundamental en un estilo elocuente y vigoroso: las declaraciones dogmáticas

... no pueden ser falsas en el sentido que no serían ya, y de ninguna manera, señales que actualizan la verdad de Jesucristo. Si tal fuera el caso, la promesa de la presencia permanente del Espíritu de Jesucristo en su Iglesia se suprimiría. No es ya la verdad que habría sido victoriosa de una vez por todas, sino las potencias de la oscuridad que se habrían llevado la victoria final. Porque esto es imposible debido a la fe en Jesucristo, la Iglesia no puede mantenerse y permanecer en la verdad "al lado", "sin" o incluso "a pesar" de las formulaciones de la fe que tienen un carácter de obligación. Éstas son realmente verdaderas y obligan en su limitación y en sus acondicionamientos históricos propios ${ }^{42}$.

El Espíritu despierta y alimenta el sensus fidelium, es decir, este sentido interior por el cual, bajo la conducta del Magisterio, el pueblo de Dios reconoce en las formulaciones de fe no la palabra de los hombres sino la Palabra de Dios que acepta y guarda con una indefectible fidelidad. Esto responde a un principio teológico fundamental, que ya lo mencionamos en varias ocasiones, la verdad cristiana es una verdad que solo ocurre en el acontecimiento eclesial siempre actual de su enunciación y que está encaminada hacia una realización de orden escatológico. Es porque la Verdad ya nos fue suministrada por el Hijo liberado de la muerte (véase Jn 8,36), exegeta del Padre (véase Jn 1,18), que por el Espíritu no somos sino "uno solo" (véase Rm 5,5; Ga 3,28), y podemos desde ahora hacer ruta con ella (véase Lc 24,15) dándole testimonio (véase Jn 18, 37-38) hasta el día del juicio (véase 5, 19-47).

${ }^{41}$ Cfr. CONGRÉGATION POUR LA DOCTRINE DE LA FOI. Mysterium Ecclesiae. In: DC (15 juillet 1973), p. 667s.

${ }^{42}$ KASPER, W. La Théologie et l'Eglise, pp. 161-162. 
Sin embargo, si la tradición no es la repetición irreflexiva del ayer, sino eso que permite en el hoy de nuestra existencia vivir del origen, y de hacerlo nuestro en formas históricas siempre nuevas, decir que las declaraciones dogmáticas no pueden ser superadas, no significa que no puedan ser el objeto de un trabajo de interpretación, ya que la Verdad es siempre mayor a la conciencia que tenemos de ella en un momento determinado de nuestra existencia. Los dogmas señalan un punto de no retorno sobre el cual la Iglesia no puede dar marcha atrás. Estableciendo fronteras, abren un espacio de libertad. En la Verdad que nos vuelve libres, recibimos nuestra fe como una herencia, un don del que debemos apropiarnos cada vez de nuevo, con todo nuestro corazón y nuestra inteligencia. No es solamente la palabra apostólica como tal, un contenido formulado de manera determinada, sino al mismo tiempo "el espíritu apostólico" que pasó a la Iglesia y que sigue viviendo en ella. Tradición e interpretación están pues vinculadas de manera indisoluble ${ }^{43}$.

\section{La interpretación de los dogmas}

Pero, después de lo anteriormente comentado, una vez que hemos dicho esto, un problema de importancia se presenta ante nosotros. Si cada tiempo histórico solo puede recibir el testimonio dogmático de la tradición e interpretarlo, ¿esta cadena de interpretaciones no nos conduce al relativismo que solo conoce las interpretaciones de las interpretaciones, las cuales, a su vez, conducen sin cesar a nuevas interpretaciones? En realidad, la cuestión consiste en saber si hay o "no hay, dentro del proceso histórico de interpretación, una verdad que exista por sí misma" 44 .

Desde la época moderna tenemos una concepción historicista y dinámica de la Verdad. No es solamente mediatizada por la historia: es historia e histórica, es un advenimiento. Esta concepción tiene el mérito de sacar la Verdad del yugo encerrado y ya dado, en el cual se encontraba desde Aristóteles pero,

\footnotetext{
${ }^{43}$ En los tiempos modernos, la investigación más fructífera en teología fundamental se refiere a la relación de la verdad con la historia. Ésta investigación se aleja oponiéndose a la verdad metafísica que siempre está bajo el signo de la misma lógica, de una coincidencia inmediata con el inicio que anula cualquier discontinuidad, diferencia y pluralidad. Esto, para establecer una relación entre la historia y la verdad que acepta plenamente a estar bajo el signo de la discontinuidad, la diferencia, la alteridad. Por tanto, somos capaces de pensar la tradición no como una reproducción de un pasado muerto, sino como producción siempre nueva. Cf. Claude Geffré. Le Christianisme au risque de l'interprétation. Paris: Cerf, CF 120, 1997, pp. 7-104.

${ }^{44}$ CTI 489.
} 
en el cristianismo, buscamos la verdad porque ésta nos ha sido entregada en Jesucristo por el Padre en el Espíritu Santo.

La cruz y la resurrección constituyen pues la entrega-tradición (Überlieferung) pura y simplemente; como tales son el primer fundamento, el contenido y el paradigma de toda tradición cristiana. La historia definitiva de Dios con los hombres no puede transmitirse como cualquier objeto histórico. No disponemos de ella; es ella la que dispone de nosotros y nos determina. La auto-entrega objetiva de Dios en Jesucristo se convierte en realidad subjetiva en nosotros por la efusión del Espíritu Santo ${ }^{45}$.

La entrega que hace de sí el Padre por el Logos en el Santo Espíritu sigue presente en la Iglesia bajo múltiples formas: en su palabra y sus obras, en la liturgia y su oración, así como en su vida entera. Las definiciones dogmáticas, como ya lo dijimos, son un elemento de la Paradosis eclesial, no se puede aislarlas del contexto de la vida eclesial para interpretarlas como si fueran puras fórmulas conceptuales.

Además, la Tradición viva del pueblo de Dios peregrino, a través de la historia, no se detiene en un punto determinado de esta historia; llega al tiempo presente que atraviesa para prolongarse en el futuro. La definición de un dogma, como lo había sostenido K. Rahner con respecto a la definición Cristológica del Concilio de Calcedonia, no es solamente un punto de llegada, es siempre también un nuevo principio ${ }^{46}$. Si una verdad de fe se convirtió en un dogma, dice el texto del CTI, se inserta para siempre en la Paradosis que progresa.

A la definición le sigue pues la recepción, es decir, la apropiación vital de este dogma en la vida comunitaria de la Iglesia, y la penetración más profunda en la verdad que atestigua. Ya que el dogma no debe ser un vestigio del tiempo pasado; debe producir frutos en la vida de la Iglesia. Por esta razón, no hay que ver solamente su significado negativo o restrictivo; debe ser entendido en su sentido positivo, que abre a la verdad ${ }^{47}$.

\footnotetext{
${ }^{45}$ KASPER, W. La Théologie et l'Église, p. 157.

46 "Nosotros tenemos no solo el derecho sino el deber de comprender esta definición de la fe como una culminación y como un principio. Debemos alejarnos de ella, no para abandonarla sino para comprenderla mejor". ED, pp. 117.

${ }^{47}$ CTI 499
} 
Tal interpretación no es un proceso puramente intelectual. No consiste solamente en la definición más precisa de los conceptos, ni en la refundición o invención de las fórmulas. Se guía, se inspira constantemente, por la acción del Espíritu Santo en la Iglesia y en el corazón de cada cristiano; se efectúa en la luz de la fe. La interpretación de los dogmas se hace en y por la vida eclesial en su totalidad ${ }^{48}$.

En la proclamación del Evangelio, a lo largo de la historia, el Espíritu Santo no deja de volver presente, en su novedad siempre actual, el misterio de Cristo a los hombres de toda raza, lengua, pueblo o nación (Ap 5,9) y eso en "su propia lengua materna" (Ca 2,8). Sin embargo, es verdad, no se pueden separar claramente contenido y forma de expresión. En efecto, y he aquí el quid del asunto, "la propia cosa no puede poseerse sino en la palabra histórica que suscita y no al lado de ella o pasando más allá de ella"49. Toda una piedra de obstáculo, incluso dentro de la Iglesia, se encuentra ligada a ese carácter irreformable de la forma misma de expresión de las declaraciones dogmáticas. Aunque nuestros conceptos estén siempre más acá de la verdad contemplada, no podemos alcanzarla sino gracias a la mediación del concepto. La CTI intenta, por su parte, responder a nuestro problema recurriendo a la unidad de la Iglesia.

En el proceso de expresión verbal de la fe, la Iglesia se creó su propio lenguaje, por el cual dio una expresión a realidades que no habían sido conocidas y percibidas antes, pero que pertenecen ahora, precisamente por esta expresión lingüística, a la Paradosis de la Iglesia y por ella a la herencia histórica de la humanidad. Como comunidad de fe, la Iglesia es una comunidad en la palabra de la confesión. Esta es la razón por la que la unidad en las palabras fundamentales de la fe forman también parte, diacrónicamente como sincrónicamente, de la unidad de la Iglesia. Estas palabras fundamentales de la fe no son revisables, aunque se proponga no perder de vista la realidad que se expresa en ellas ${ }^{50}$.

\footnotetext{
${ }^{48}$ Nosotros no podemos sino evocar el hecho de que el ministerio de la Paradosis y interpretación a sido confiado a la Iglesia en su conjunto, y que en el seno de la Iglesia, pertenece a los obispos, establecido dentro de la sucesión apostólica (LG, 19), interpretar auténticamente la Tradición de la fe (DV, 10). En comunión con el Obispo de Roma, a quien el ministerio de la unidad es conferido de una manera particular, ellos, colegialmente tienen el poder de definir los dogmas, e interpretarlos auténticamente. Cf. SESBOÜÉ, B. Le magistère à l'épreuve: op cit.

${ }^{49}$ ED 230

${ }^{50}$ CTI 500. La CTI agrega que "ninguna época puede retroceder en lo que ha sido formulado dentro del dogma por el Espíritu Santo teniendo como clave de lectura la Escritura. Esto no
} 
La respuesta del CTI debe ser completada ya que se podría creer que esta irreformabilidad no es otra cosa que una exigencia sociológica. " $E l$ dogma debe entenderse como un concepto con una función dinámica, como resultado y apertura de un encuentro de la Iglesia con el evangelio, como expresión y hacer posible el amor eclesial" ${ }^{51}$. Si la última palabra del dogma es la comunión fraterna, es precisamente porque al final de la historia la fe desaparecerá.

Incluso en la hipótesis contraria, incluso si un determinado relativismo dogmático estaría en el centro del cristianismo, incluso si cada tiempo estaría en la capacidad de reiniciar desde cero la aventura cristiana, sería necesario volver siempre de nuevo a las formulaciones originarias de los dogmas; si no es a través de términos que cambian a lo largo de la historia, lo único que pudiéramos encontrar son los estados de conciencia de un tiempo dado y no la fe de la Iglesia ${ }^{52}$. No podríamos entender el sentido de las declaraciones dogmáticas sin esta irreformabilidad de las expresiones de las que la Iglesia, en una etapa de su historia, se sirvió para fijarlas.

El artículo de fe es, pues, una mediación doctrinal que contiene la verdad de la que da prueba; precisamente porque es verdadero, dirige, más allá de sí mismo, al misterio de la verdad divina. Eso significa como lo afirma la CTI que la interpretación de dogmas es

\begin{abstract}
... un camino que nos conduce de la palabra exterior al centro de su significado y finalmente, a la única y eterna palabra de Dios. Esta es la razón por la que la interpretación de los dogmas no va de una palabra y de una fórmula particular a otros términos; va más bien de las palabras, de las imágenes y los conceptos a la verdad de la cosa que contienen. Por tanto, finalmente todo conocimiento de fe es una anticipación de la visión eterna de Dios frente a frente ${ }^{53}$.
\end{abstract}

excluye que en una época posterior, nuevos puntos de vista y nuevas formulaciones aparezcan". CTI 497.

${ }^{51}$ KASPER, Walter. Dogma unter dem Wort Gottes, p. 139.

${ }^{52} \mathrm{Si}$ es el caso, llegaremos a la misma constatación del fracaso de la investigación sobre la vida de Jesús que hizo Albert Schweitzer: los que gustan de hablar de teología negativa no tendrán ninguna dificultad para aplicar su concepción al resultado de la investigación sobre la vida de Jesús, ya que el resultado es negativo. El Jesús de Nazaret que se nos es presentado ese Jesús jamás existió. Ésta no es sino una figura proyectada por el racionalismo del siglo XVIII, animada después por el liberalismo y disfrazada después como teología moderna.

${ }^{53}$ CTI 476. 


\section{Conclusión}

Ante el horror a la subjetividad que domina la fe cristiana y ante el peligro permanente de cosificarse en fórmulas doctrinales, es preciso insistir en que el objeto de fe del cristianismo no es una lista determinada de premisas lógicas, sino la misma persona de Jesucristo. Benedicto XVI lo ha dicho con claridad: “... no se comienza a ser cristiano por una decisión ética o una gran idea, sino por el encuentro con un acontecimiento, con una Persona, que da un nuevo horizonte a la vida y, con ello, una orientación decisiva" (Deus caritas est 1). Es la persona de Jesús reconocida en la fe como Cristo y Señor, único Evangelio de la Misericordia del Padre, el acontecimiento salvífico absoluto de quien quieren dar testimonio los dogmas. El dogma no anula, corrige o altera el Evangelio; es su actualización histórica, un "es decir". Consecuentemente, la teología dogmática no es la defensa partisana de afirmaciones abstractas, sino que encuentra su razón de ser en la dependencia esencial a la persona concreta de Jesucristo como verdad que libera, como camino en el tiempo, hacia un Dios siempre nuevo en su infinitud.

\section{Referencias bibliográficas}

ALCAIN, J. A. La Tradición. Bilbao: Universidad de Deusto, 1998.

COMMISSION THÉOLOGIQUE INTERNATIONALE. "L'interprétation des dogmes". In: Documentation Catholique N 2006 (1990), pp. 499504 .

CONGAR, Y. La Foi et la Théologie. Paris: Desclée, 1962.

CONGRÉGATION POUR LA DOCTRINE DE LA FOI. "Mysterium Ecclesiae". In: Documentation Catholique № 1636 (1973), pp. 664-670.

DENZINGER, E. El Magisterio de la Iglesia. Barcelona: Herder, 1963.

GADAMER, H. Vérité et Méthode. Paris: Seuil, 1976.

GEFFRE, C. Le Christianisme au risque de l'interprétation. Paris : Cerf, 1977.

IRÉNÉE DE LYON. Contre les Hérésies. Paris: Cerf, 1984.

JUAN XXIII. "Discurso de apertura del Concilio, el 11 octubre de 1962". Acta Apostolicae Sedis 54 (1962), p. 792. 
KASPER, W. Dogma unter dem Wort Gottes. Mainz: Matthias-GrünewaldVerlag, 1965.

KASPER, W. Dogme et Evangile. Paris: Casterman, 1967.

KASPER, W. Teología e Iglesia. Barcelona: Herder, 1990.

KASPER, W. La Théologie et l'Église. Paris: Cerf, 1990.

LE ROY, E. “Qu'est-ce qu'un dogme”. La Quinzaine 63 (1905), pp. 495-526.

METZ, J.-B. La foi dans l'histoire et dans la société. Paris: Cerf, 1999.

NOEMI, J. "Sobre la credibilidad del dogma cristiano". Teologia y Vida XVL (2004), pp. 258-272.

POULAT, E. Historia, Dogma y Crítica. Madrid: Ed Taurus, 1974.

RAHNER, K. "Problèmes actuels de Christologie". In: Écrits Théologiques.

Paris: DDB, 1957, pp. 115-181.

RAHNER, K. “Qu'est-ce qu'un énoncé dogmatique?”. In: Écrits

Théologiques 7. Paris: DDB. 1967, pp. 239 -241.

SESBOÜE, B. "Le procès contemporain de Chalcédoine. Bilan et perspectives”. Recherches des Sciences Religieuses 65/1 (1977), pp. $45-80$.

SESBOÜE, B. Histoire des Dogmes IV. Paris: Desclée, 1996.

SESBOÜE, B. Le magistère à l'épreuve. Paris: DDB, 2001.

David de la Torre SSCC

Diploma de estudios doctorales por el Instituto Católico de París Profesor Principal Ordinario de la Facultad de Teología de la Pontificia Universidad Católica del Ecuador Quito / Ecuador E-mail: ddelatorre@puce.edu.ec

Recebido em: 10/11/15

Aprovado em: 01/03/16 